\title{
Neuro-ophthalmic sarcoidosis
}

This article was published in the following Dove Press journal:

Eye and Brain

13 March 2012

Number of times this article has been viewed

\author{
Robert P Baughman' \\ Kenneth L Weiss ${ }^{2}$ \\ Karl C Golnik ${ }^{3}$ \\ 'Department of Medicine, \\ ${ }^{2}$ Department of Radiology, \\ ${ }^{3}$ Department of Ophthalmology, \\ University of Cincinnati Medical \\ Center, Cincinnati, Ohio, USA
}

Correspondence: Robert P Baughman I00I Holmes, Eden Ave,

Cincinnati, OH 45267, USA

Email bob.baughman@uc.edu
Abstract: Neuro-ophthalmic disease occurs in about a third of patients with neurosarcoidosis. Optic nerve involvement is the most common manifestation, but other cranial nerves and the optic chiasm can be involved. However, there are several other common diseases that cause optic neuropathy, including multiple sclerosis. The diagnosis of sarcoidosis can often be made based on the multi-organ nature of the disease and ancillary testing. Most patients with neuro-ophthalmic sarcoidosis require systemic therapy. While corticosteroids are usually the first step in therapy, cytotoxic agents such as methotrexate and azathioprine have been useful as steroid-sparing agents for chronic disease. The monoclonal antibodies directed against tumor necrosis factor have been reported as effective in refractory cases of neuro-ophthalmic disease.

Keywords: sarcoidosis, methotrexate, infliximab, multiple sclerosis, optic neuritis, prednisone

\section{Introduction}

Sarcoidosis is a multi-organ disease. While the lung is the most common organ involved, ocular disease is seen in at least a quarter of patients. ${ }^{1}$ In most large series of sarcoidosis patients, neurologic disease has been reported in about $5 \%-10 \%$ of cases. ${ }^{2}$ However, in this review, we will concentrate on the specific entity of neuro-ophthalmic sarcoidosis, most commonly manifested by involvement of the anterior visual system (optic nerve and chiasm) and/or involvement of the oculomotoric cranial nerves. Neuro-ophthalmic involvement occurs in up to one third of patients with neurologic sarcoidosis $(2 \%-3 \% \text { of all sarcoidosis cases })^{3}$

\section{Etiology and genetics of sarcoidosis}

The cause of sarcoidosis remains elusive. Several potential environmental agents have been identified in epidemiologic studies. ${ }^{4}$ There has been a focus on potential infectious agents ${ }^{5}$ in the past few years, several studies have focused on the possibility of Propiniumbacter acnes as a potential cause for sarcoidosis. ${ }^{6}$ This includes an animal model of diffuse granulomatous disease that resembles sarcoidosis induced by $P$. acnes. ${ }^{7}$

Another potential causative agent for sarcoidosis is an atypical form of mycobacteria. In some patients with sarcoidosis, there is evidence of proteins exclusive for mycobacteria in the granulomas. Antibodies to these proteins are also present in some sarcoidosis. ${ }^{8-10}$ Detailed studies have demonstrated that these proteins may be expressed by an as yet unidentified mycobacterium species, which is closely related to Mycobacteria tuberculosis. ${ }^{11}$ Animal models of disseminated granulomatous disease have also been generated using these antigens. ${ }^{12}$ 
One difficulty with these studies is that only a subset of sarcoidosis patients demonstrates antibodies to either of these agents. This could mean that there is more than one cause of sarcoidosis. It could also be due to a bystander effect of a nonspecific immune response. Sarcoidosis can lead to a polyclonal immune response. ${ }^{13}$ Therefore, one may be only identifying a generalized immune response, not a specific response to a single antigen.

Several studies have highlighted the importance of underlying genetic predisposition to the disease. ${ }^{14}$ The initiation of the granulomatous response is the interaction of the antigen presenting cell and the $\mathrm{CD} 4$ positive $\mathrm{T}$ cell through human leukocyte antigen (HLA) Class II and T cell receptor. ${ }^{15}$ In the granulomatous disease beryliosis, a specific HLA molecule is associated with a markedly increased risk for disease in exposed individuals. ${ }^{16}$ While such a strong association has not been found with sarcoidosis, there have been several candidate HLA genes associated with the disease. ${ }^{17}$

The genetic aspect is highlighted by familial aggregation that occurs with the disease..$^{18}$ For a patient being evaluated for sarcoidosis with at least one first degree relative with sarcoidosis, there is a greater than ten-fold increased risk for the patient having the disease. ${ }^{19}$ This is an important clinical point. For example, if evaluating a patient with optic neuritis, a positive family history for sarcoidosis markedly increases the chances one is dealing with a sarcoidosis patient.

Some specific genes have been associated with increased risk for ocular disease (Table 1). These include polymorphisms of heat shock protein $70 / \mathrm{Hom}^{20}$ and cytotoxic T-lymphocyte antigen $4,{ }^{21}$ and matrix metalloproteinase- $1 .{ }^{22}$ Blau's syndrome is a familial disease similar to sarcoidosis. Genetic polymorphisms have been reported in nucleotidebinding oligomerization domain 2 genes in patients with Blau's syndrome, but not in most cases of sarcoidosis. ${ }^{23}$ However, there has been a report of increased incidence

Table I Genes associated with ocular disease

\begin{tabular}{lll}
\hline Gene & First author & Comment \\
\hline DRBI*040I & Rossman $^{102}$ & $\begin{array}{l}\text { Association with eye disease in } \\
\text { African Americans but not Caucasians }\end{array}$ \\
HSPIHom & Spagnolo $^{20}$ & $\begin{array}{l}\text { Associated with uveitis in Europe } \\
\text { CTLA-4 }\end{array}$ \\
MMP-I & Nattori $^{21}$ & $\begin{array}{l}\text { Study in Japan } \\
\text { Study in Japan, found no increased } \\
\text { risk of disease }\end{array}$ \\
NOD2 & Okafuji2 $^{24}$ & $\begin{array}{l}\text { Association between early onset } \\
\text { sarcoidosis with uveitis as well as } \\
\text { patients with Blau's syndrome }\end{array}$ \\
\hline
\end{tabular}

Abbreviations: HSP/Hom, heat shock protein 70/Hom; CTLA-4, cytotoxic T-lymphocyte antigen 4; MMP-I, matrix metalloproteinase-I; NOD2, nucleotidebinding oligomerization domain 2 gene. of certain polymorphisms of the nucleotide-binding oligomerization domain 2 genes for both Blau's syndrome and early onset sarcoidosis. ${ }^{24}$

Detailed genetic studies have been performed in large cohorts of sarcoidosis patients, including families with the disease. These have identified some features associated with an increased risk for disease. Perhaps the largest number of associations have been with the HLA. ${ }^{17}$ Gene wide association studies have also identified correlations between clusters of organ involvement and certain areas of the chromosomes. These include ocular/skin/joint involvement and chromosome 10q25 (Likelihood ratio $=2.93, P=0.001) .{ }^{25}$ There has been less information regarding the potential genetic predisposition for neurosarcoidosis. Some of this may be due to the relative rarity of neurosarcoidosis. Rybicki and associates reported an association between neurologic and lymphatic involvement and chromosome 7p22 (Likelihood ratio $=5.16, P=0.00004) .{ }^{25}$

\section{Epidemiology of neuro-ophthalmic sarcoidosis}

The reported incidence of ophthalmic sarcoidosis varies from less than $10 \%$ to more than $80 \% .^{1}$ In some cases, this is due to different methods of defining eye involvement, since most patients do not undergo biopsy of the eye itself. Clinical criteria for definite or probable sarcoidosis have been developed. For patients with known sarcoidosis (based on biopsy) and no other cause for eye disease identified, the presence of uveitis, lacrimal gland swelling, or optic neuritis was classified as definite ocular sarcoidosis and unexplained blindness was classified probable ocular sarcoidosis. ${ }^{26}$ In patients who present with uveitis, there is proposed criteria for the diagnosis of sarcoidosis as definite, presumed, probable, or possible based on biopsy and other features. ${ }^{27}$

Another factor influencing rate of disease is underlying race. African Americans and Japanese have an increased rate of ocular sarcoidosis. ${ }^{28,29}$ In studies where the same criteria for ocular disease was used, there was an increased rate in African American compared to Caucasians in the United States. ${ }^{29}$ In a study comparing sarcoidosis in Finland to Japan, Japanese patients had a five-fold increased rate of ocular disease. ${ }^{30}$

There does not seem to be a similar racial difference for neurosarcoidosis. The incidence varies from $5 \%-15 \%{ }^{3,29,31,32}$ Similar to neurosarcoidosis, neuro-ophthalmic sarcoidosis does not seem to be different in terms of underlying race or gender compared to the general sarcoidosis population. ${ }^{33,34}$ 


\section{Symptoms and signs of neuro-ophthalmic sarcoidosis}

The major symptoms of neuro-ophthalmic sarcoidosis are loss of vision and double vision. Visual loss can be central, peripheral, or both. There is no pattern of visual loss specific to sarcoidosis. The visual field loss can be severe, but normal visual acuity has been reported and patients may even have mild asymptomatic visual loss. ${ }^{35}$ Pain may accompany the visual loss when the optic nerve is inflamed. Less commonly, double vision results from ocular misalignment due to involvement of the oculomotor, trochlear, or abducens nerve(s). Rarely, anisocoria due to Horner's syndrome or tonic pupil occurs. ${ }^{33}$ Table 2 lists the other ophthalmic manifestations encountered in patients with sarcoid optic neuritis.

Sarcoidosis of the optic nerve can produce a variety of optic disc appearances. Acutely, the optic disc most commonly appears either swollen (Figure 1A) or normal (retrobulbar optic neuritis). Occasionally the optic disc may be swollen and exudate can be seen in the retina (Figure 1B); this is called neuroretinitis. Optic nerve head granuloma is seen rarely (Figure 1C). If the optic nerve is permanently damaged, optic atrophy develops (Figure 1D). Oculomotoric cranial nerve palsies may be complete and produce characteristic ocular motility patterns but mild involvement may lead to double vision without obvious paresis. Peripheral facial nerve involvement will appear as a Bell's palsy with varying degrees of hemifacial weakness. The anisocoria of Horner syndrome should be greater in dim illumination than bright and there is typically mild ptosis ipsilateral to the smaller (Horner) pupil. In contradistinction, anisocoria due to Adie tonic pupil should be greater in bright illumination and the larger (Adie) pupil will not react well to a light stimulus. Table 2 lists the eye examination findings of two series of optic neuropathy due to sarcoidosis. Other portions of the eye can be affected by disease and this should be considered in evaluating sarcoidosis patients.

\section{Diagnosis of neuro-ophthalmic sarcoidosis}

The criteria for diagnosis of neuro-ophthalmic sarcoidosis depend on whether the patient has been diagnosed with systemic sarcoidosis or other illnesses which may manifest similar neuro-ophthalmic symptoms. For those with known sarcoidosis and absent history or ancillary evidence of potentially mimicking conditions such as multiple sclerosis, malignancy, or infection, neuro-ophthalmic sarcoidosis may be presumed when both clinical and imaging findings are consistent with/suggestive of this diagnosis.

One of the most common dilemmas for the clinician is to differentiate multiple sclerosis from sarcoidosis. Table 3 lists some of the ocular, neurologic, and extra ocular features that may be useful in distinguishing these two conditions. Most of these are relatively useful, since there remains no single test that can differentiate one from another condition. There are some tests that are useful in helping to make the diagnosis of sarcoidosis. ${ }^{36,37} \mathrm{~A}$ biopsy of any tissue that demonstrates noncaseating granulomas with no alternative cause is the usual criteria for diagnosis. ${ }^{38}$ In addition to pathology, multiorgan involvement supports the diagnosis of sarcoidosis.

However, in the absence of known sarcoidosis, other etiologies are more common and must be considered. Optic neuropathy may be due to myriad mechanisms but inflammation (optic neuritis), infection, ischemia, and compression are most common. In particular, optic neuritis associated with multiple sclerosis may present similarly in both the eye and brain. ${ }^{37}$ Multiple sclerosis can lead to both uveitis and optic nerve disease, so other features must be sought to separate these two conditions. ${ }^{39}$ While overlap exists, brain/orbital magnetic resonance imaging (MRI) with and without contrast can often help differentiate multiple sclerosis from neurosarcoidosis based on the sometimes characteristic distribution and appearance of white matter lesions in the former; and more importantly, the potential presence of non-myelin related masses, leptomeningeal, or dural involvement in the latter. Spinal MRI and follow-up imaging studies may add further clarity.

Neuromyelitis optica can cause optic neuritis and with the recent ability to test for the neuromyelitis optica antibody (aquaporine-4-antibodies) it is becoming a more commonly recognized condition. ${ }^{40}$ Ischemic optic neuropathy is the most common type of optic neuropathy in older adults and also may mimic the presentation of sarcoidosis. In the United States infectious optic neuropathy is less common but Bartonella henselae (cat scratch disease) often causes neuroretinitis indistinguishable from sarcoidosis. Compressive optic neuropathy by tumor typically causes much slower visual loss than sarcoidosis. Other cranial neuropathies may also be caused by multiple sclerosis, ischemia, and compression, and each of these entities must be considered in patients without known sarcoidosis.

Importantly, sarcoidosis is a multi-focal and multi-organ disease. Therefore, the presence of multiple areas of involvement help increase the certainty of the diagnosis. This includes the finding of more than one area of involvement of the central nervous system. ${ }^{33,41}$ These include other cranial 

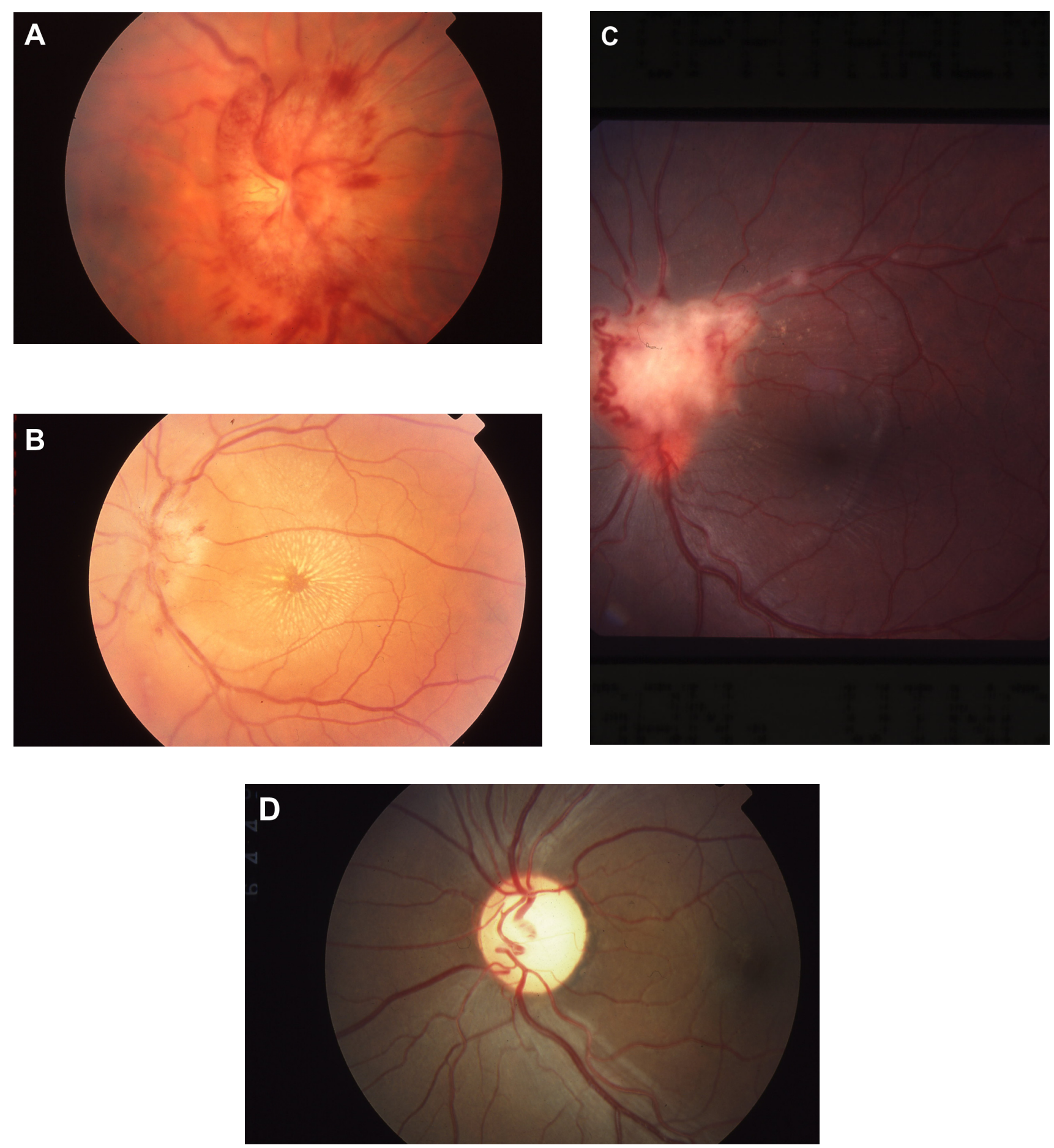

Figure I Fundus findings in sarcoid optic neuropathy. A shows marked swelling with nerve fiber layer hemorrhages. The exudates in $\mathbf{B}$ form a star figure centered on the macula. C shows a mass on the disc consistent with granuloma and also shows sheathing of retinal vessels and optociliary shunt vessels. (D) Optic atrophy.

nerve involvement, especially the seventh nerve. Also mass lesions and meningitis can be found. Imaging studies to include computer tomography and $\mathrm{MRI}^{42}$ currently play an integral role in the diagnosis and management of patients with sarcoidosis, with MRI the exam of choice for evaluating the neuro-axis and orbits. High resolution multiplanar, multiparametric brain/orbital MRI with and without gadolinium contrast administration to include fat-suppressed or fat/water separation sequencing through the orbits is recommended for optimal evaluation. Figure 2 demonstrates several MRI changes identified in sarcoidosis patients which were useful in diagnosing neuro-ophthalmic disease. 
Table 2 Eye examination in patients with optic neuritis due to sarcoidosis

\begin{tabular}{lll}
\hline & Frohman $^{35}$ & Koczman $^{33}$ \\
\hline $\begin{array}{l}\text { Number of cases with optic } \\
\text { neuropathy }\end{array}$ & 24 & $14 \%$ \\
$\begin{array}{l}\text { Eye exam } \\
\text { Normal }\end{array}$ & \\
Pallor & $15 \%$ & \\
Disc edema & $55 \%$ & $0 \%$ \\
Periphlebitis/sheathing & $26 \%$ & $36 \%$ \\
Optic disc granuloma & $14 \%$ & $57 \%$ \\
Anterior uveitis & $10 \%$ & Not reported \\
\hline
\end{tabular}

Note: *Out of a total of 20 patients diagnosed with neuro-ophthalmic sarcoidosis.

Figure 2A demonstrates an MRI showing ill-defined contrast-enhancing inferiororbital tissue that was found to be granulomatous inflammation. The patient was also hypercalcemic. She responded well to corticosteroid and methotrexate therapy. In one report of the contrast MRI findings of 19 patients with neuro-ophthalmic sarcoidosis, 16 demonstrated pathologic contrast enhancement including involvement of the optic nerve (nine cases), leptomeninges (three cases), cerebral parenchyma (three cases), and one each of optic chiasm, optic radiations, and cavernous sinus..$^{33}$ Also the optic chiasm can be involved by a mass or infiltrative process. ${ }^{43}$ In some cases, this can be associated with other areas of inflammation in the brain or spine. MRI can be useful in not only identifying the lesion in the optic chiasm, but also identifying other areas of involvement, especially leptomeningeal enhancement. Seen in approximately $40 \%$ of patients with neurosarcoidosis, leptomeningeal involvement with diffuse or focal/multi-focal enhancement is the most commonly reported imaging abnormality. ${ }^{2}$ Leptomeningeal disease may represent other inflammatory processes (eg, tuberculosis) or carcinomatosis. Most enhancing mass lesions are not sarcoid but benign or malignant tumors.

Figure 3 provides a general approach to the diagnosis of neuro-ophthalmic sarcoidosis. For patients with known sarcoidosis, the presence of one or more features listed can lead to a definite diagnosis of neuro-ophthalmic sarcoidosis. For those without a known diagnosis of sarcoidosis, the level of certainty of the diagnosis is lower. There are supplementary laboratory tests that support the diagnosis of sarcoidosis. These include an elevated angiotensin converting enzyme, soluble intereukin-2 receptor, or lysozyme level. ${ }^{44}$ For patients with neurologic disease a lymphocytic meningitis is consistent with sarcoidosis, ${ }^{31}$ but less commonly seen with multiple sclerosis. There is also the finding of granulomatous disease of the neuro-ophthalmic area without evidence
Table 3 Features comparing neuro-ophthalmic sarcoidosis and multiple sclerosis

\begin{tabular}{|c|c|c|}
\hline & Sarcoidosis & $\begin{array}{l}\text { Multiple } \\
\text { sclerosis }\end{array}$ \\
\hline Race: black:white & $3-5: 1$ & $\mathrm{I}: 2-5$ \\
\hline Female predominance & Yes & Yes \\
\hline Anterior uveitis & Yes & Yes \\
\hline Cranial nerve paralysis & Yes (especially 7th) & Occasional \\
\hline \multicolumn{3}{|c|}{ Chest imaging (chest $\mathbf{x}$-ray or computer tomography scan) } \\
\hline Hilar/mediastinal & $50 \%-60 \%$ & $0 \%$ \\
\hline \multicolumn{3}{|l|}{ Adenopathy } \\
\hline Parenchymal lung disease & $30 \%-50 \%$ & $0 \%$ \\
\hline \multicolumn{3}{|c|}{ Extraocular/Neurologic features associated with sarcoidosis } \\
\hline \multirow[t]{4}{*}{ Skin } & Erythema nodosum & \\
\hline & Lupus pernio & \\
\hline & Macular popular & \\
\hline & lesions & \\
\hline \multirow[t]{2}{*}{ Hepatic } & Increased alkaline & \\
\hline & phosphatase & \\
\hline \multirow[t]{4}{*}{ Calcium metabolism } & Hypercalcuria & \\
\hline & Hypercalcemia & \\
\hline & Elevated vitamin & \\
\hline & D-I,25 & \\
\hline \multicolumn{3}{|l|}{ Laboratory testing } \\
\hline $\begin{array}{l}\text { Angiotensin converting } \\
\text { enzyme elevation }\end{array}$ & $60 \%$ & \\
\hline Gallium/PET scan & $50 \%-50 \%$ & \\
\hline Pathology & $\begin{array}{l}\text { Noncaseating } \\
\text { granuloma }\end{array}$ & \\
\hline \multicolumn{3}{|l|}{ Cerebral spinal fluid findings } \\
\hline Increased lymphocytes & Common & $\begin{array}{l}\text { Mild increase in } \\
\text { lymphocytes }\end{array}$ \\
\hline Increased protein & Common & Can occur \\
\hline Low glucose & Unusual & Rare \\
\hline Oligoclonal bands & Can occur & Very common \\
\hline $\operatorname{lgG}$ index & Commonly increased & $\begin{array}{l}\text { Almost always } \\
\text { increased }\end{array}$ \\
\hline
\end{tabular}

Abbreviation: PET, positron emission tomography.

of granulomatous disease elsewhere. It is not clear that this is sarcoidosis, although since it affects two organ systems (the eye and the nervous system), it meets the criteria for diagnosis of sarcoidosis. ${ }^{36}$ Since the treatment and outcome appear the same for patients with extra-ocular disease, we would consider these sarcoidosis patients.

\section{Management of neuro-ophthalmic sarcoidosis}

There are no evidence-based recommendations regarding the treatment of neuro-ophthalmic sarcoidosis. There have been several agents used to treat sarcoidosis. Most of the evidence-based recommendations of therapy for sarcoidosis are based on treatment of pulmonary disease. ${ }^{45}$

Figure 4 summarizes an approach to the management of neuro-ophthalmic sarcoidosis. Since there is a high incidence 

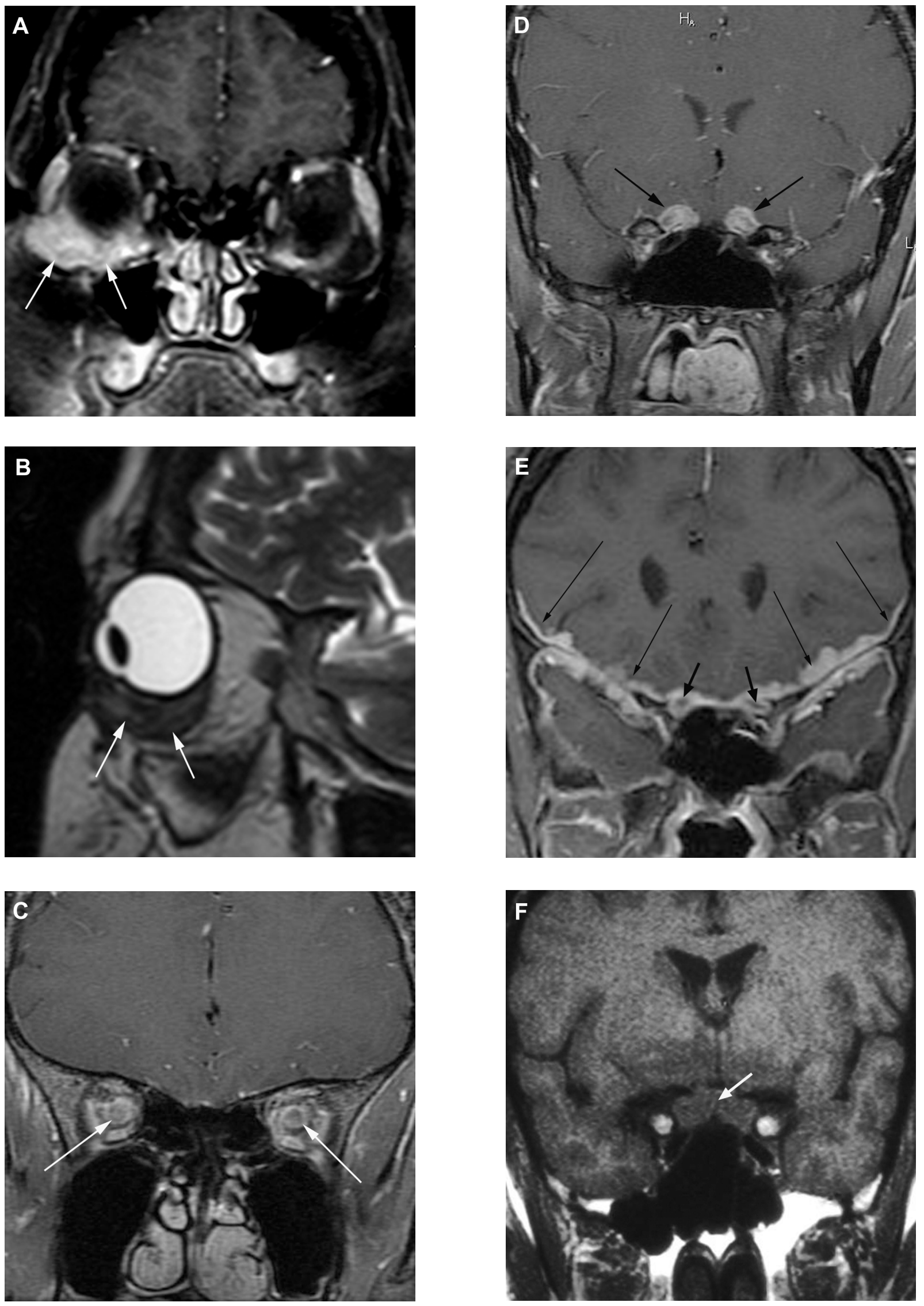

Figure 2 (Continued) 

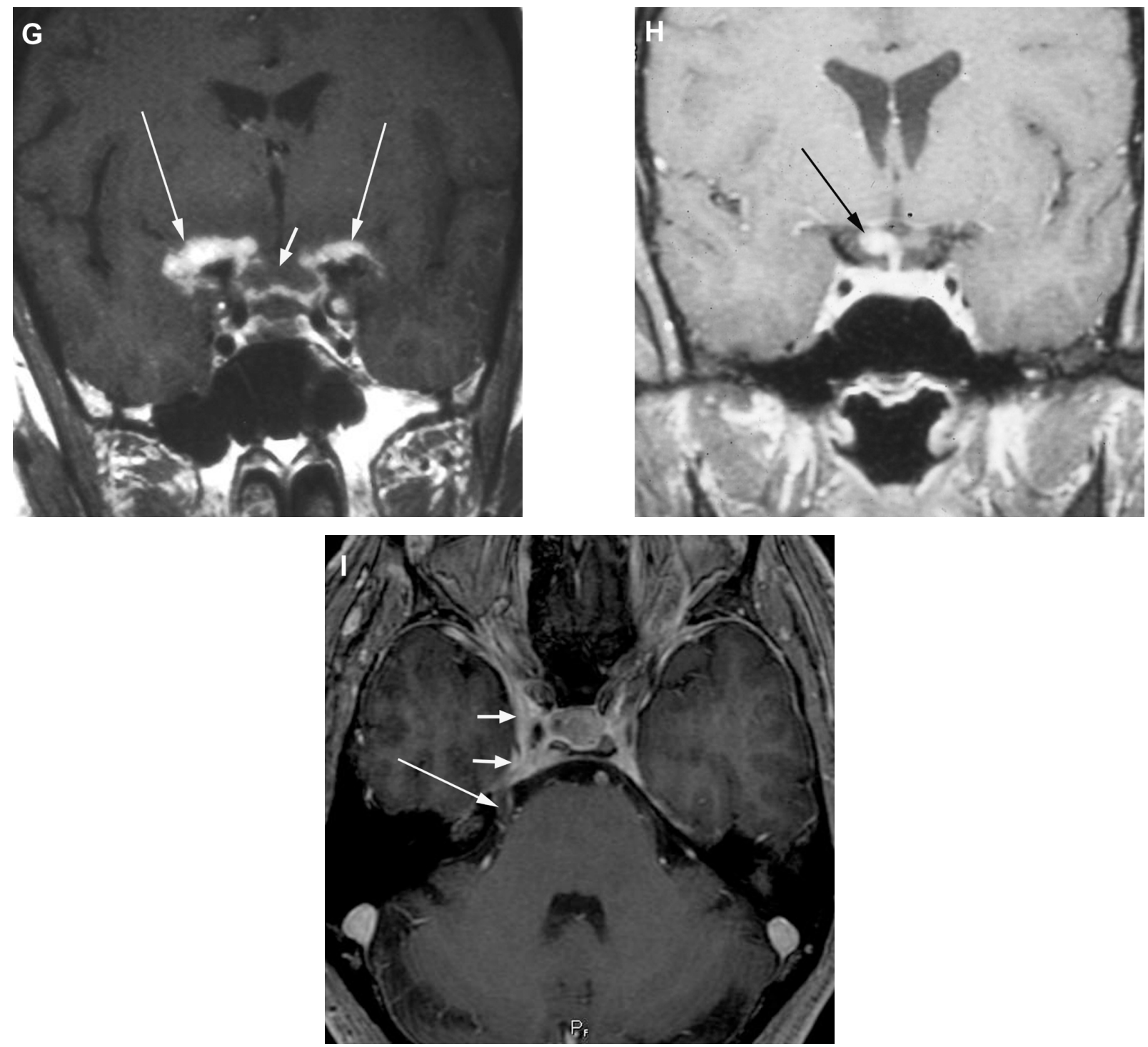

Figure 2 Magnetic resonance imaging images of manifestations of neuro-ophthalamic sarcoidosis. (A) Coronal fat-suppressed TI-weighted post-contrast and (B) sagittal T2-weighted images demonstrate an ill-defined contrast-enhancing, low T2-signal inferior right orbital mass (arrows) surrounding the insertion of the inferior rectus muscle. Subsequent biopsy revealed granulomatous inflammatory tissue compatible with sarcoid. In another patient, coronal fat-suppressed TI-weighted post-contrast images reveal abnormal enhancement along the bilateral intraconal (C) and pre-chiasmal (D) optic nerves. In a third patient, (E) a coronal fat-suppressed TI-weighted post-contrast image reveals thick abnormal enhancement about the bilateral optic nerves (short arrows) and more extensively along the bilateral leptomeninges and dura (long arrows). In a fourth patient, presenting with blindness, a coronal pre-contrast TI-weighted image (F) and corresponding post-contrast image (G) demonstrate a swollen optic chiasm (short arrows) with thick leptomeningeal enhancement about and beyond the chiasm bilaterally (long arrows). In a fifth patient, a coronal fat-suppressed TI-weighted post-contrast image (H) reveals asymmetric right-sided involvement of the optic chiasm (arrow). In a sixth patient, presenting with right sided cranial nerves III and V abnormalities, an axial fat-suppressed TIweighted post-contrast image (I) reveals involvement of the right cavernous sinus (short arrows) and along the cisternal portion of the ipsilateral trigeminal nerve (long arrow).

of other ocular findings in these patients, a detailed eye examination should be performed. For patients with uveitis, especially anterior uveitis, topical therapy with corticosteroids may be an effective adjuvant therapy. ${ }^{1}$ Evaluation for cataracts and glaucoma due to the sarcoidosis and/or corticosteroid therapy should be monitored during therapy.

While spontaneous recovery has been reported for acute sarcoid optic neuropathy, ${ }^{46}$ this is rare. Most patients will require long term systemic therapy as outlined in Figure 4. Specific recommendations regarding administration and monitoring have been published elsewhere. ${ }^{47,48}$ While some have reported a poor outcome for optic neuropathy associated with neurosarcoidosis, ${ }^{32}$ others have found that early, aggressive therapy was associated with a favorable outcome. ${ }^{31,49}$

For neuro-ophthalmic disease itself, one should approach treatment in the same manner as neurosarcoidosis. ${ }^{2}$ In that situation, systemic corticosteroid therapy remains the most rapid and effective initial treatment. In some cases, intravenous pulse methylprednisolone is needed, 


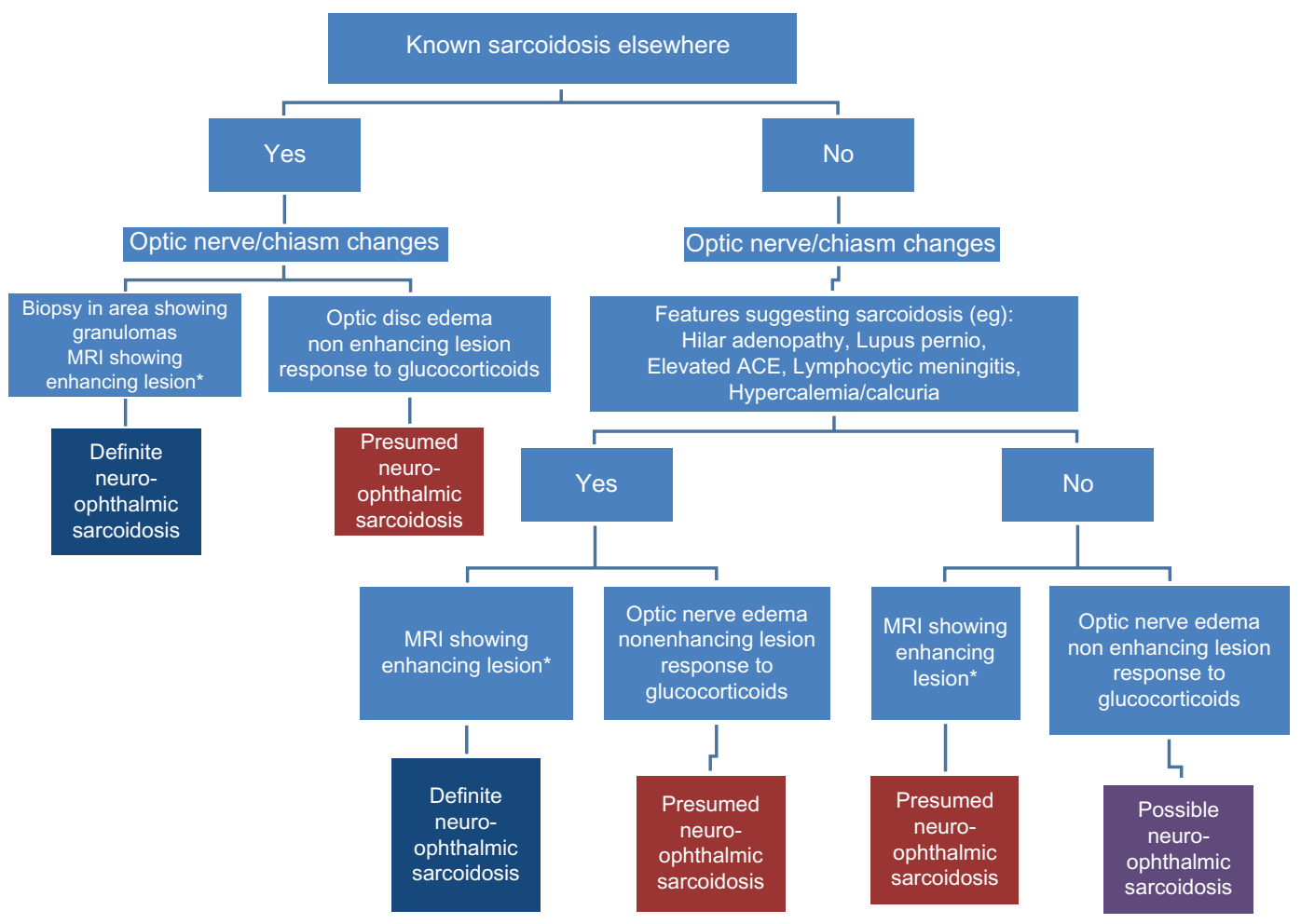

Figure 3 An approach to diagnosis of neuro-ophthalmic sarcoidosis. For patients with known sarcoidosis elsewhere, the diagnostic certainty is higher than for those who do not have biopsy evidence of granulomatous disease.

Note: *Enhancing lesion consistent with neurosarcoidosis.

Abbreviations: $\mathrm{ACE}$, angiotensin-converting enzyme; MRI, magnetic resonance imaging.

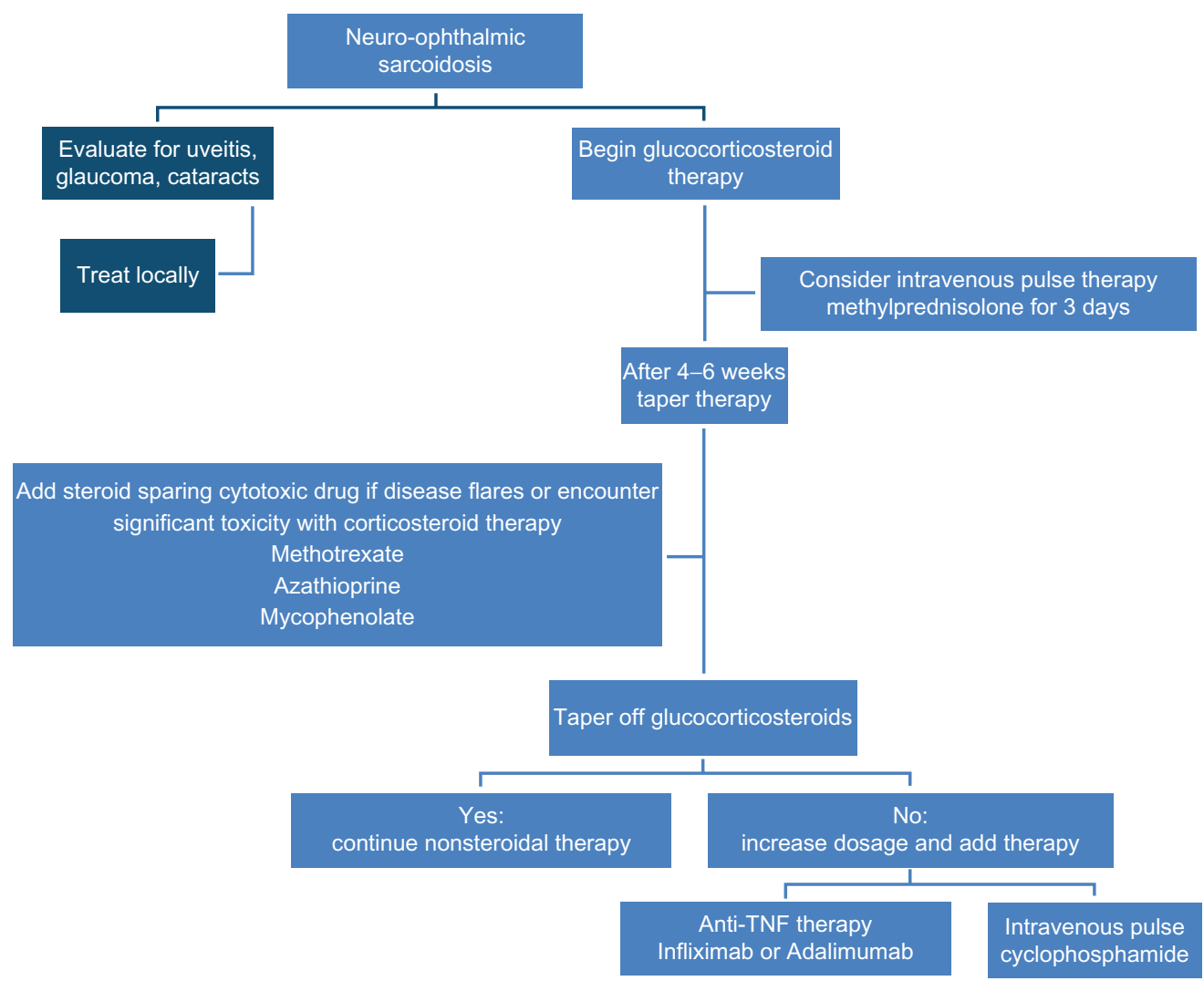

Figure 4 An approach to neuro-ophthalmic sarcoidosis. Management includes evaluation for other ocular manifestations, which may be responsive to local therapy. Abbreviation: TNF, tumor necrosis factor. 
especially if there is an initial poor responsive to oral therapy. ${ }^{3,50,51}$ While corticosteroids are effective for initial therapy, their prolonged use is associated with significant toxicity. Therefore steroid sparing alternatives are often employed. ${ }^{31,52}$ Our approach is to add a cytotoxic agent early in treatment unless the patient is highly responsive to initial corticosteroids.

Among the cytotoxic agents, methotrexate has been studied for the longest period..$^{3,31,52,53}$ For neurosarcoidosis patients, treatment with methotrexate has been effective. . $^{3,32}$ In one series, methotrexate was successful in controlling disease in 17 of $28(61 \%)$ of cases. ${ }^{31}$ It has also been reported as effective in ocular inflammation. ${ }^{54}$ In a retrospective study of 365 sarcoidosis patients with any ocular disease treated with methotrexate at one institution, 281 (77\%) controlled the disease as either the single systemic agent or in combination with other systemic therapies. ${ }^{55}$ Others have reported a similar response rate for methotrexate in treatment of optic neuritis. ${ }^{52}$ There has been one report of reversible optic neuropathy occurring with methotrexate therapy. ${ }^{56}$ The routine use of folic acid supplementation with methotrexate therapy has been shown to reduce methotrexate toxicity without affecting efficacy of the drug. ${ }^{57}$

Azathioprine has been used as an alternative to methotrexate for both neurologic sarcoidosis ${ }^{32}$ and chronic uveitis. ${ }^{58}$ Azathioprine either alone or in combination with low dose prednisone has been effective in treating neuromyelitis optica. ${ }^{59}$ Since azathioprine is less likely to lead to drug induced hepatitis than methotrexate, it is a drug which has been used without toxicity in sarcoidosis patients with significant hepatic disease. ${ }^{60}$ The drug is metabolized by the thiopurine S-methyltransferase (TPMT) enzyme. Polymorphisms of TPMT have been associated with differences in drug levels, including no biologic activity of the enzyme. In patients with low levels of active TPMT, significant bone marrow toxicity has been reported. ${ }^{61}$ Measurement of TMPT levels or screening for polymorphisms may be useful. ${ }^{62}$ Overall, the drug appears to be more toxic than other cytotoxic agents used for ocular disease. ${ }^{58}$

Mycophenolate mofetil (mycophenolate) has been used as an alternative to azathioprine for solid organ transplants for more than a decade. It has been used increasingly for patients with other conditions such as myasthenia gravis and dermatomyositis. In one retrospective study, it was better tolerated and more rapid in onset than either methotrexate or azathioprine for patients with chronic uveitis. ${ }^{58}$ Its reported use in sarcoidosis is much more limited, but there have been small series reporting effectiveness, ${ }^{63,64}$ including for uveitis. ${ }^{65}$ It has also been reported as useful in treating neurosarcoidosis either alone ${ }^{32,66}$ or in combination with anti-TNF antibodies. ${ }^{67}$

Intermittent intravenous cyclophosphamide has been reported as effective in treating refractory neurosarcoidosis. ${ }^{31,68}$ However, the drug is associated with significantly more toxicity than other cytotoxic agents and therefore usually reserved for patients refractory to other treatments. ${ }^{47}$ Among the toxicities encountered with cyclophosphamide is bladder cancer, which is dose and duration dependent. Most cases of toxicity are encountered in patients on oral dosing and have received at least 1 year of therapy. ${ }^{69}$

In the past few years, monoclonal antibodies that block tumor necrosis factor (anti-TNF) have been proved effective in treating refractory sarcoidosis. Infliximab is a chimeric monoclonal antibody that has been reported as effective in case series $^{70,71}$ and in double-blind placebo-controlled trials. ${ }^{72,73}$ For refractory ocular disease, infliximab has proved quite effective. ${ }^{71,74,75}$ The drug has also been effective for neurosarcoidosis which has not responded to other treatments, including cyclophosphamide. ${ }^{76}$ Infliximab has been successfully used to treat optic neuropathy refractory to other treatments. ${ }^{71,77,78}$ However, the drug is associated with significant toxicity including increased risk for tuberculosis and fungal infections, worsening congestive heart failure, and potential increased risk for malignancy.$^{79}$ Infliximab rarely can cause optic neuropathy and demyelinating peripheral and central diseases.

Adalimumab is a humanized monoclonal antibody against TNF. Compared to infliximab, it appeared to be less effective, ${ }^{80}$ but that may be a reflection of the lower doses used in the early treatment protocols. ${ }^{79}$ With the use of higher doses, similar to those employed in Crohn's disease, ${ }^{81,82}$ the drug appears to be quite effective in refractory ocular sarcoidosis, ${ }^{83}$ including in seven of eight patients with optic neuropathy. ${ }^{84}$ Since the drug is a humanized antibody, it has been used in patients who had previous toxicity with infliximab. ${ }^{55,85}$ However, over half of the sarcoidosis patients treated with adalimumab for more than 6 months for their ocular disease had to discontinue the drug due to recurrent infections or severe allergic reactions to the injections. ${ }^{55}$ Like infliximab, adalimumab is associated with increased risk for tuberculosis and fungal infections, worsening congestive heart failure, and potential increased risk for malignancy. ${ }^{79}$

Not all anti-TNF therapies are the same. Etanercept is the soluble TNF receptor, which acts as an antagonist to the agent. It was reported as effective for refractory cutaneous sarcoidosis. ${ }^{86}$ However, the drug was not found effective for pulmonary sarcoidosis in an open label prospective trial. ${ }^{87}$ In double-blind, placebo-controlled trials, the drug was not 
found effective for chronic uveitis ${ }^{88}$ or sarcoidosis associated ocular disease. ${ }^{89}$

One of the toxicities of anti-TNF therapy is the potential to cause a demyelinating disease such as multiple sclerosis. ${ }^{90}$ Optic neuropathy has been reported with both infliximab ${ }^{91-94}$ and adalimumab treatments. ${ }^{94-96}$ Several of these cases occurred in patients with Crohn's disease, who are usually treated with higher doses of anti-TNF therapy than those with rheumatoid arthritis. In a review of the literature, Simsek et al identified 15 cases at the time of their report. ${ }^{94}$ At the time of this report, this class of drugs had been given to more than a million patients, but the true frequency for this complication is not known. Eight of the 15 patients had been treated with infliximab, while only two had received adalimumab. This difference could have been the later introduction of adalimumab to the market compared to infliximab. The authors recommended that patients be screened for worsening of neurologic or ophthalmic symptoms. For neuro-ophthalmic patients, it should be remembered that patients could get worse rather than better with anti-TNF therapy. If in doubt, one should strongly consider stopping the anti-TNF therapy and treating the patient with high dose glucocorticoids. ${ }^{94}$

Other treatments have been used in a limited number of cases. Hydroxychloroquine has been reported by some authors. ${ }^{3,32}$ Hydroxychloroquine can lead to ocular toxicity, specifically retinal disease, although rare at low doses. ${ }^{97}$ Rituximab has been used to treat some cases of optic neuropathy, ${ }^{98}$ and has also been reported as effective in treating some sarcoidosis patients. ${ }^{99}$ Because of differences in toxicities, these drugs may be useful in selected cases. Cyclosporine has also been reported as useful in selected cases. ${ }^{33,34}$ In a randomized trial of cyclosporine for pulmonary sarcoidosis, the drug was not steroid sparing. ${ }^{100}$ The drug is also associated with significant toxicity including hypertension, renal failure, opportunistic infections, and increased risk of infection. Radiation may be useful if there is a single area of persistent disease. ${ }^{101}$

While no single agent is effective for neuro-ophthalmic sarcoidosis, there are some general recommendations that can be used as guidelines in treating the individual patient (Table 4). Most patients seem to respond to this stepwise approach. $^{33,34}$ The clinician and patient need to balance the various factors as they decide on which treatment regimen to use. The regimen should be reviewed on a regular basis and a new approach should be considered whenever a less than ideal response is encountered or if toxicity is limiting treatment.
Table 4 General guidelines for treating neuro-ophthalmic sarcoidosis

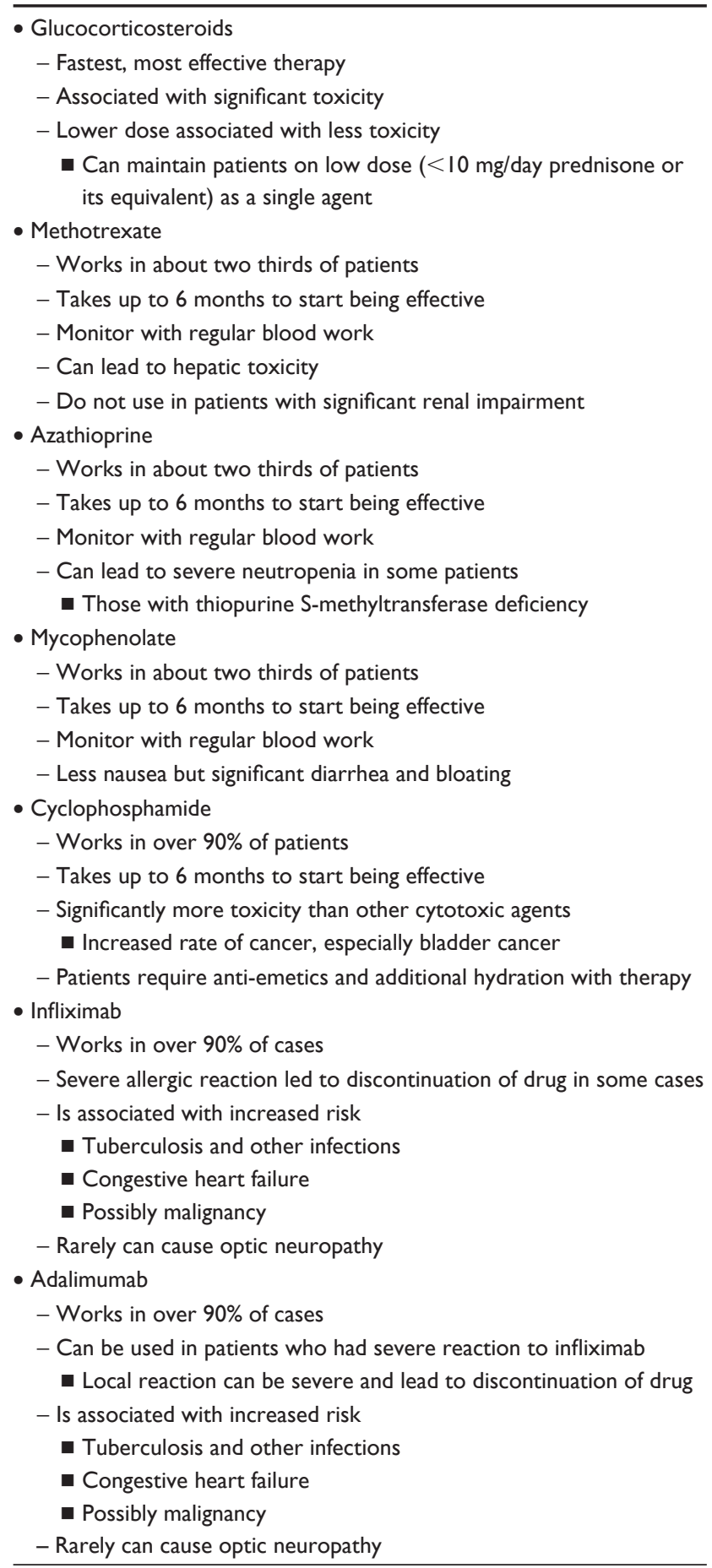

Note: See text for further details.

\section{Conclusion}

Neuro-ophthalmic disease is an important manifestation of sarcoidosis. It is important to differentiate sarcoidosis from other conditions, since the treatment and outcome can be quite different. Neuro-ophthalmic sarcoidosis is often responsive to corticosteroid therapy. The use of steroid 
sparing alternatives can minimize the long term risk from these drugs.

\section{Disclosure}

The authors report no conflicts of interest in this work.

\section{References}

1. Baughman RP, Lower EE, Kaufman AH. Ocular sarcoidosis. Semin Respir Crit Care Med. 2010;31(4):452-462.

2. Lower EE, Weiss KL. Neurosarcoidosis. Clin Chest Med. 2008;29(3): 475-492.

3. Zajicek JP, Scolding NJ, Foster O, et al. Central nervous system sarcoidosis - diagnosis and management. QJM. 1999;92(2):103-117.

4. Newman LS, Rose CS, Bresnitz EA, et al. A case control etiologic study of sarcoidosis: environmental and occupational risk factors. $\mathrm{Am}$ J Respir Crit Care Med. 2004;170(12):1324-1330.

5. Oswald-Richter KA, Drake WP. The etiologic role of infectious antigens in sarcoidosis pathogenesis. Semin Respir Crit Care Med. 2010;31(4):375-379.

6. Eishi Y, Suga M, Ishige I, et al. Quantitative analysis of mycobacterial and propionibacterial DNA in lymph nodes of Japanese and European patients with sarcoidosis. J Clin Microbiol. 2002;40(1): 198-204.

7. Kishi J, Nishioka Y, Kuwahara T, et al. Blockade of Th1 chemokine receptors ameliorates pulmonary granulomatosis in mice. Eur Respir J. 2011;38(2):415-424.

8. Dubaniewicz A, Trzonkowski P, Dubaniewicz-Wybieralska M, Dubaniewicz A, Singh M, Mysliwski A. Mycobacterial heat shock protein-induced blood $\mathrm{T}$ lymphocytes subsets and cytokine pattern: comparison of sarcoidosis with tuberculosis and healthy controls. Respirology. 2007;12(3):346-354.

9. Chen ES, Wahlstrom J, Song Z, et al. T cell responses to mycobacterial catalase-peroxidase profile a pathogenic antigen in systemic sarcoidosis. J Immunol. 2008;181(12):8784-8796.

10. Oswald-Richter KA, Culver DA, Hawkins C, et al. Cellular responses to mycobacterial antigens are present in bronchoalveolar lavage fluid used in the diagnosis of sarcoidosis. Infect Immun. 2009;77(9):3740-3748

11. Drake WP, Dhason MS, Nadaf M, et al. Cellular recognition of Mycobacterium tuberculosis ESAT-6 and KatG peptides in systemic sarcoidosis. Infect Immun. 2007;75(1):527-530.

12. Swaisgood CM, Oswald-Richter K, Moeller SD, et al. Development of a sarcoidosis murine lung granuloma model using Mycobacterium superoxide dismutase A peptide. Am J Respir Cell Mol Biol. 2011;44(2): $166-174$

13. Hunninghake GW, Crystal RG. Mechanisms of hypergammaglobinemia in pulmonary sarcoidosis: site of increased antibody production and role of T-lymphocyte. J Clin Invest. 1981;67(1):86-96.

14. Barnard J, Rose C, Newman L, et al. Job and industry classifications associated with sarcoidosis in A Case-Control Etiologic Study of Sarcoidosis (ACCESS). J Occup Environ Med. 2005;47(3): 226-234

15. Moller DR, Chen ES. Genetic basis of remitting sarcoidosis: triumph of the trimolecular complex? Am J Respir Cell Mol Biol. 2002;27(4): 391-395.

16. Richeldi L, Sorrentino R, Saltini C. HLA-DPB1 Glutamate 69: a genetic marker of beryllium disease. Science. 1993;262(5131):242-244.

17. Grunewald J. Review: role of genetics in susceptibility and outcome of sarcoidosis. Semin Respir Crit Care Med. 2010;31(4):380-389.

18. Rybicki BA, Maliarik MJ, Major M, Popovich J Jr, Iannuzzi MC. Epidemiology, demographics, and genetics of sarcoidosis. Semin Respir Infect. 1998;13(3):166-173.

19. Rybicki BA, Iannuzzi MC, Frederick MM, et al. Familial aggregation of sarcoidosis: A case-control etiologic study of sarcoidosis (ACCESS) Am J Respir Crit Care Med. 2001;164(11):2085-2091.
20. Spagnolo P, Sato H, Marshall SE, et al. Association between heat shock protein 70/Hom genetic polymorphisms and uveitis in patients with sarcoidosis. Invest Ophthalmol Vis Sci. 2007;48(7):3019-3025.

21. Hattori N, Niimi T, Sato S, et al. Cytotoxic T-lymphocyte antigen 4 gene polymorphisms in sarcoidosis patients. Sarcoidosis Vasc Diffuse Lung Dis. 2005;22(1):27-32.

22. Ninomiya $\mathrm{S}$, Niimi T, Shimizu $\mathrm{S}$, et al. Matrix metalloproteinase-1 polymorphism of promoter region in sarcoidosis and tuberculosis patients. Sarcoidosis Vasc Diffuse Lung Dis. 2004;21(1):19-24.

23. Rybicki BA, Maliarik MJ, Bock CH, et al. The Blau syndrome gene is not a major risk factor for sarcoidosis. Sarcoidosis Vasc Diffuse Lung Dis. 1999;16(2):203-208

24. Okafuji I, Nishikomori R, Kanazawa N, et al. Role of the NOD2 genotype in the clinical phenotype of Blau syndrome and early-onset sarcoidosis. Arthritis Rheum. 2009;60(1):242-250.

25. Rybicki BA, Sinha R, Iyengar S, Gray-McGuire C, Elston RC, Iannuzzi MC Genetic linkage analysis of sarcoidosis phenotypes: the sarcoidosis genetic analysis (SAGA) study. Genes Immun. 2007;8(5):379-386.

26. Judson MA, Baughman RP, Teirstein AS, Terrin ML, Yeager H Jr. Defining organ involvement in sarcoidosis: the ACCESS proposed instrument. ACCESS Research Group. A Case Control Etiologic Study of Sarcoidosis. Sarcoidosis Vasc Diffuse Lung Dis. 1999;16(1): $75-86$.

27. Herbort CP, Rao NA, Mochizuki M. International criteria for the diagnosis of ocular sarcoidosis: results of the first International Workshop On Ocular Sarcoidosis (IWOS). Ocul Immunol Inflamm. 2009;17(3):160-169.

28. Ohara K, Okubo A, Sasaki H, Kamata K. Intraocular manifestations of systemic sarcoidosis. Jpn J Ophthalmol. 1992;36(4):452-457.

29. Baughman RP, Teirstein AS, Judson MA, et al. Clinical characteristics of patients in a case control study of sarcoidosis. Am J Respir Crit Care Med. 2001;164(10 Pt 1):1885-1889.

30. Pietinalho A, Ohmichi M, Lofroos AB, Hiraga Y, Selroos O. The prognosis of sarcoidosis in Finland and Hokkaido, Japan. A comparative five-year study of biopsy-proven cases. Sarcoidosis Vasc Diffuse Lung Dis. 2000;17(2):158-166.

31. Lower EE, Broderick JP, Brott TG, Baughman RP. Diagnosis and management of neurologic sarcoidosis. Arch Intern Med. 1997;157(16): 1864-1868.

32. Pawate S, Moses H, Sriram S. Presentations and outcomes of neurosarcoidosis: a study of 54 cases. QJM. 2009;102(7):449-460.

33. Koczman JJ, Rouleau J, Gaunt M, Kardon RH, Wall M, Lee AG. Neuro-ophthalmic sarcoidosis: the University of Iowa experience. Semin Ophthalmol. 2008;23(3):157-168.

34. Frohman LP, Grigorian R, Bielory L. Neuro-ophthalmic manifestations of sarcoidosis: clinical spectrum, evaluation, and management. J Neuroophthalmol. 2001;21(2):132-137.

35. Frohman LP, Guirgis M, Turbin RE, Bielory L. Sarcoidosis of the anterior visual pathway: 24 new cases. J Neuroophthalmol. 2003;23(3): 190-197.

36. Hunninghake GW, Costabel U, Ando M, et al. ATS/ERS/WASOG statement on sarcoidosis. American Thoracic Society/European Respiratory Society/World Association of Sarcoidosis and other Granulomatous Disorders. Sarcoidosis Vasc Diffuse Lung Dis. 1999;16(2):149-173.

37. Baughman RP, du Bois RM, Lower EE. Sarcoidosis. Lancet. 2003; 361(9363):1111-1118.

38. Judson MA. The diagnosis of sarcoidosis. Clin Chest Med. 2008;29(3): 415-427.

39. Scott TF, Yandora K, Kunschner LJ, Schramke C. Neurosarcoidosis mimicry of multiple sclerosis: clinical, laboratory, and imaging characteristics. Neurologist. 2010;16(6):386-389.

40. Jacob A, Matiello M, Wingerchuk DM, Lucchinetti CF, Pittock SJ, Weinshenker BG. Neuromyelitis optica: changing concepts. J Neuroimmunol. 2007;187(1-2):126-138.

41. Frohman LP, Grigorian R, Bielory L. Neuro-ophthalmic manifestations of sarcoidosis: clinical spectrum, evaluation, and management J Neuroophthalmol. 2001;21(2):132-137. 
42. Braswell RA, Kline LB. Neuro-ophthalmologic manifestations of sarcoidosis. Int Ophthalmol Clin. 2007;47(4):67-77.

43. Lee AG, Lin DJ, Kaufman M, Golnik KC, Vaphiades MS, Eggenberger E. Atypical features prompting neuroimaging in acute optic neuropathy in adults. Can J Ophthalmol. 2000;35(6):325-330.

44. Baughman RP, Costabel U. Markers of sarcoidosis. In: Baughman RP, editor. Sarcodiosis. New York, NY: Taylor and Francis Group; 2006: 435-462.

45. Baughman RP, Culver DA, Judson MA. A concise review of pulmonary sarcoidosis. Am J Respir Crit Care Med. 2011;183(5):573-581.

46. Galetta S, Schatz NJ, Glaser JS. Acute sarcoid optic neuropathy with spontaneous recovery. J Clin Neuroophthalmol. 1989;9(1):27-32.

47. Baughman RP, Selroos O. Evidence-based approach to the treatment of sarcoidosis. In: Gibson PG, Abramson M, Wood-Baker R, Volmick J, Hensley M, Costabel U, editors. Evidence-Based Respiratory Medicine. Malden, MA: Blackwell Publishing Ltd; 2005:491-508.

48. Baughman RP, Costabel U, Lower EE. Drug therapy for interstitial lung disease. In: Baughman RP, du Bois RM, editors. Diffuse Lung Disease: A Practical Approach. New York, NY: Springer; 2011:101-120.

49. Scott TF, Yandora K, Valeri A, Chieffe C, Schramke C. Aggressive therapy for neurosarcoidosis: long-term follow-up of 48 treated patients. Arch Neurol. 2007;64(5):691-696.

50. Eggenberger ER. Inflammatory optic neuropathies. Ophthalmol Clin North Am. 2001;14(1):73-82.

51. Allen RK, Sellars RE, Sandstrom PA. A prospective study of 32 patients with neurosarcoidosis. Sarcoidosis Vasc Diffuse Lung Dis. 2003;20(2):118-125.

52. Myers TD, Smith JR, Wertheim MS, Egan RA, Shults WT, Rosenbaum JT. Use of corticosteroid sparing systemic immunosuppression for treatment of corticosteroid dependent optic neuritis not associated with demyelinating disease. Br J Ophthalmol. 2004;88(5):673-680.

53. Lower EE, Baughman RP. The use of low dose methotrexate in refractory sarcoidosis. Am J Med Sci. 1990;299(3):153-157.

54. Smith JR, Rosenbaum JT. A role for methotrexate in the management of non-infectious orbital inflammatory disease. $\mathrm{Br} J$ Ophthalmol. 2001;85(10):1220-1224.

55. Baughman RP, Lower EE, Ingledue R, Kaufman AH. Management of ocular sarcoidosis. Sarcoidosis Vasc Diffuse Lung Dis. 2012. In press.

56. Clare G, Colley S, Kennett R, Elston JS. Reversible optic neuropathy associated with low-dose methotrexate therapy. J Neuroophthalmol. 2005;25(2):109-112.

57. Morgan SL, Baggott JE, Vaughn WH, et al. Supplementation with folic acid during methotrexate therapy for rheumatoid arthritis. A double-blind, placebo-controlled trial. Ann Intern Med. 1994;121(11): 833-841.

58. Galor A, Jabs DA, Leder HA, et al. Comparison of antimetabolite drugs as corticosteroid-sparing therapy for noninfectious ocular inflammation. Ophthalmology. 2008;115(10):1826-1832.

59. Bichuetti DB, Lobato de Oliveira EM, Oliveira DM, Amorin de Souza N, Gabbai AA. Neuromyelitis optica treatment: analysis of 36 patients. Arch Neurol. 2010;67(9):1131-1136.

60. Kennedy PT, Zakaria N, Modawi SB, et al. Natural history of hepatic sarcoidosis and its response to treatment. Eur J Gastroenterol Hepatol. 2006;18(7):721-726.

61. Escousse A, Mousson C, Santona L, et al. Azathioprine-induced pancytopenia in homogenous thioprine methyltransferase-deficient renal transplant recipeints: a family study. Transplant Proc. 1995;27(2):1739-1742.

62. Hagaman JT, Kinder BW, Eckman MH. Thiopurine S-methyltranferase testing in idiopathic pulmonary fibrosis: a pharmacogenetic costeffectiveness analysis. Lung. 2010;188(2):125-132.

63. Moudgil A, Przygodzki RM, Kher KK. Successful steroid-sparing treatment of renal limited sarcoidosis with mycophenolate mofetil. Pediatr Nephrol. 2006;21(2):281-285.

64. Kouba DJ, Mimouni D, Rencic A, Nousari HC. Mycophenolate mofetil may serve as a steroid-sparing agent for sarcoidosis. $\mathrm{Br} J$ Dermatol. 2003;148(1):147-148.
65. Bhat P, Cervantes-Castaneda RA, Doctor PP, Anzaar F, Foster CS. Mycophenolate mofetil therapy for sarcoidosis-associated uveitis. Ocul Immunol Inflamm. 2009;17(3):185-190.

66. Androdias G, Maillet D, Marignier R, et al. Mycophenolate mofetil may be effective in CNS sarcoidosis but not in sarcoid myopathy. Neurology. 2011;76(13):1168-1172.

67. Moravan M, Segal BM. Treatment of CNS sarcoidosis with infliximab and mycophenolate mofetil. Neurology. 2009;72(4):337-340.

68. Doty JD, Mazur JE, Judson MA. Treatment of corticosteroid-resistant neurosarcoidosis with a short-course cyclophosphamide regimen. Chest. 2003;124(5):2023-2026.

69. Talar-Williams C, Hijazi YM, Walther MM, et al. Cyclophosphamideinduced cystitis and bladder cancer in patients with Wegener granulomatosis. Ann Intern Med. 1996;124(5):477-484.

70. Doty JD, Mazur JE, Judson MA. Treatment of sarcoidosis with infliximab. Chest. 2005;127(3):1064-1071.

71. Baughman RP, Bradley DA, Lower EE. Infliximab for chronic ocular inflammation. Int J Clin Pharmacol Ther. 2005;43(1):7-11.

72. Baughman RP, Drent M, Kavuru M, et al. Infliximab therapy in patients with chronic sarcoidosis and pulmonary involvement. Am J Respir Crit Care Med. 2006;174(7):795-802.

73. Rossman MD, Newman LS, Baughman RP, et al. A double-blind, randomized, placebo-controlled trial of infliximab in patients with active pulmonary sarcoidosis. Sarcoidosis Vasc Diffuse Lung Dis. 2006;23(3):201-208.

74. Joseph A, Raj D, Dua HS, Powell PT, Lanyon PC, Powell RJ. Infliximab in the treatment of refractory posterior uveitis. Ophthalmology. 2003;110(7):1449-1453.

75. Petropoulos IK, Vaudaux JD, Guex-Crosier Y. Anti-TNF-alpha therapy in patients with chronic non-infectious uveitis: the experience of Jules Gonin Eye Hospital. Klin Monatsbl Augenheilkd. 2008;225(5):457-461.

76. Sodhi M, Pearson K, White ES, Culver DA. Infliximab therapy rescues cyclophosphamide failure in severe central nervous system sarcoidosis. Respir Med. 2009;103(2):268-273.

77. Katz JM, Bruno MK, Winterkorn JM, Nealon N. The pathogenesis and treatment of optic disc swelling in neurosarcoidosis: a unique therapeutic response to infliximab. Arch Neurol. 2003;60(3): 426-430.

78. Prendiville C, O'Doherty M, Moriarty P, Cassidy L. The use of infliximab in ocular inflammation. Br J Ophthalmol. 2008;92(6): 823-825.

79. Baughman RP, Lower EE, Drent M. Inhibitors of tumor necrosis factor (TNF) in sarcoidosis: who, what, and how to use them. Sarcoidosis Vasc Diffuse Lung Dis. 2008;25(2):76-89.

80. Baughman RP. Tumor necrosis factor inhibition in treating sarcoidosis: the American experience. Revista Portuguesa de Pneumonologia. 2007;13:S47-S50.

81. Sandborn WJ, Rutgeerts P, Enns R, et al. Adalimumab induction therapy for Crohn disease previously treated with infliximab: a randomized trial. Ann Intern Med. 2007;146(12):829-838.

82. Sandborn WJ, Hanauer SB, Rutgeerts P, et al. Adalimumab for maintenance treatment of Crohn's disease: results of the CLASSIC II trial. Gut. 2007;56(9):1232-1239.

83. Kamphuis LS, Lam-Tse WK, Dik WA, et al. Efficacy of adalimumab in chronically active and symptomatic patients with sarcoidosis. $\mathrm{Am} \mathrm{J}$ Respir Crit Care Med. 2011;184(10):1214-1216.

84. Erckens RJ, Mostard RL, Wijnen PA, Schouten JS, Drent M. Adalimumab successful in sarcoidosis patients with refractory chronic non-infectious uveitis. Graefes Arch Clin Exp Ophthalmol. 2011. Epub Nov 27.

85. Sandborn WJ, Hanauer S, Loftus EV Jr, et al. An open-label study of the human anti-TNF monoclonal antibody adalimumab in subjects with prior loss of response or intolerance to infliximab for Crohn's disease. Am J Gastroenterol. 2004;99(10):1984-1989.

86. Khanna D, Liebling MR, Louie JS. Etanercept ameliorates sarcoidosis arthritis and skin disease. J Rheumatol. 2003;30(8):1864-1867. 
87. Utz JP, Limper AH, Kalra S, et al. Etanercept for the treatment of stage II and III progressive pulmonary sarcoidosis. Chest. 2003;124(1):177-185.

88. Foster CS, Tufail F, Waheed NK, et al. Efficacy of etanercept in preventing relapse of uveitis controlled by methotrexate. Arch Ophthalmol. 2003;121(4):437-440.

89. Baughman RP, Lower EE, Bradley DA, Raymond LA, Kaufman A. Etanercept for refractory ocular sarcoidosis: results of a double-blind randomized trial. Chest. 2005;128(2):1062-1067.

90. Bensouda-Grimaldi L, Mulleman D, Valat JP, Autret-Leca E. Adalimumab-associated multiple sclerosis. J Rheumatol. 2007;34(1):239-240.

91. Felekis T, Katsanos K, Christodoulou D, Asproudis I, Tsianos EV. Reversible bilateral optic neuritis after Infliximab discontinuation in a patient with Crohn's disease. J Crohns Colitis. 2009;3(3):212-214.

92. Ouakaa-Kchaou A, Gargouri D, Trojet S, et al. Retrobulbar optic neuritis associated with infliximab in a patient with Crohn's disease. J Crohns Colitis. 2009;3(2):131-133.

93. Mumoli N, Niccoli G, Scazzeri F, Picchietti S, Greco A, Cei M. Infliximab-induced retrobulbar optic neuritis. QJM. 2007;100(8):531

94. Simsek I, Erdem H, Pay S, Sobaci G, Dinc A. Optic neuritis occurring with anti-tumour necrosis factor alpha therapy. Ann Rheum Dis. 2007;66(9):1255-1258.
95. Chung JH, Van Stavern GP, Frohman LP, Turbin RE. Adalimumabassociated optic neuritis. J Neurol Sci. 2006;244(1-2):133-136.

96. Li SY, Birnbaum AD, Goldstein DA. Optic neuritis associated with adalimumab in the treatment of uveitis. Ocul Immunol Inflamm. 2010;18(6):475-481.

97. Yam JC, Kwok AK. Ocular toxicity of hydroxychloroquine. Hong Kong Med J. 2006;12(4):294-304.

98. Pellkofer HL, Krumbholz M, Berthele A, et al. Long-term follow-up of patients with neuromyelitis optica after repeated therapy with rituximab. Neurology. 2011;76(15):1310-1315.

99. Belkhou A, Younsi R, El Bouchti I, El Hassani S. Rituximab as a treatment alternative in sarcoidosis. Joint Bone Spine. 2008;75(4):511-512.

100. Wyser CP, van Schalkwyk EM, Alheit B, Bardin PG, Joubert JR. Treatment of progressive pulmonary sarcoidosis with cyclosporin A a randomized controlled trial. Am J Respir Crit Care Med. 1997;156(5):1371-1376.

101. Gelwan MJ, Kellen RI, Burde RM, Kupersmith MJ. Sarcoidosis of the anterior visual pathway: successes and failures. $J$ Neurol Neurosurg Psychiatry. 1988;51(12):1473-1480.

102. Rossman MD, Thompson B, Frederick M, et al. HLA-DRB1*1101: a significant risk factor for sarcoidosis in blacks and whites. Am J Hum Genet. 2003;73(4):720-735.
Eye and Brain

\section{Publish your work in this journal}

Eye and Brain is an international, peer-reviewed, open access journal focusing on clinical and experimental research in the field of neuro-ophthalmology. All aspects of patient care are addressed within the journal as well as basic research. Papers covering original research, basic science, clinical and epidemiological studies, reviews and

\section{Dovepress}

evaluations, guidelines, expert opinion and commentary, case reports and extended reports are welcome. The manuscript management system is completely online and includes a very quick and fair peer-review system, which is all easy to use. Visit http://www.dovepress.com/ testimonials.php to read real quotes from published authors. 